\title{
ALTERAÇÃO DO CARÁTER HIDROFÍLICO DE FILMES DE QUITOSANA POR TRATAMENTO DE PLASMA DE HMDS
}

Odilio B. G. Assis

Embrapa Instrumentação Agropecuária, Rua XV de Novembro, 1452, 13560-970 São Carlos, SP - Brasil

Recebido em 31/3/09; aceito em 9/9/09; publicado na web em 24/2/10

\begin{abstract}
CHANGE IN HYDROPHILIC CHARACTERISTICS OF CHITOSAN FILMS BY HMDS PLASMA TREATMENT. Alteration in hydrophilicity feature of chitosan films by hexamethyldisilazane (HMDS) cold-plasma treatment is evaluated. All treated films were colorless and transparent with no apparent textural changes. The effect on surfaces was characterized through contact angle measurements, degree of swelling and water vapor permeation. A significant reduction in all of the hydrophilicity parameters was observed. It is assumed that the HMDS treatment forms nonpolar silicone type structures. The goal is to investigate the formation of a stable hydrophobic barrier in order to increase the chitosan films usefulness in packaging applications.
\end{abstract}

Keywords: chitosan; plasma deposition; HMDS.

\section{INTRODUÇÃO}

A quitosana é um amino polissacarídeo que ocorre naturalmente na natureza em pequenas quantidades nas paredes celulares e esporos de alguns fungos (Mucor e Zygomicetes), ${ }^{1}$ ou pode ser obtida pela hidrólise alcalina da quitina, principal componente dos exoesqueletos dos artrópodes. O termo quitosana não identifica um único composto, mas copolímeros formados por unidades monoméricas de $\beta(1-4)$ 2-acetamida-2-deoxi-D-glicose (ou D-glucosamina), em diferentes graus de polimerização dispostos em uma cadeia linear similar à da celulose com exceção da substituição dos grupos hidroxila na posição 2 por grupos amino. ${ }^{2}$

O que faz da quitosana um material de interesse é seu amplo espectro antimicrobiano ${ }^{3}$ que, associado à biocompatibilidade e à biodegradabilidade, a torna particularmente interessante para aplicações na agricultura, medicina, meio ambiente e alimentos.

A quitosana é solúvel somente em $\mathrm{pH}$ próximos ao seu $\mathrm{pk}_{\mathrm{a}}(\sim 6,3)$, formando um polímero catiônico pela protonação dos grupos amino. Se vertido sobre superfície plana apolar, após a evaporação do solvente, resulta em filmes com razoáveis propriedades mecânicas ${ }^{4}$ que têm sido avaliados como potenciais materiais para uso em revestimentos comestíveis de frutos e hortaliças, ${ }^{4}$ para a formação de cartilagens e tecidos artificiais, ${ }^{6}$ e como membranas de separação ou de complexação de íons de metais tóxicos em meio aquoso. ${ }^{7}$

Os filmes de quitosana apresentam, na condição seca, baixa permeação a gases, inferiores aos medidos para PET ou PVC e a demais filmes de base biológica como glúten e celulose ${ }^{8} \mathrm{e}$, adicionalmente, tem sido mostrado que a permeação de $\mathrm{CO}_{2}$ é superior à de $\mathrm{O}_{2} \mathrm{O}$ que pode vir a ser de interesse na confecção de embalagens com atmosferas controladas. ${ }^{8,9}$ Embora apresente múltiplas propriedades, seu uso como material de engenharia é limitado por apresentar alta afinidade por água.

Do ponto de vista químico, a quitosana é uma macromolécula com predominância de grupos amino caracterizados por ligações covalentes $(\mathrm{N}-\mathrm{H})$, onde a eletronegatividade dessas ligações gera sítios de alta polaridade, tornando favorável o rearranjo de moléculas de águas em seu entorno. Essa característica associada aos grupos acetamido, que também são polares, caracteriza assim um material com alto grau de hidrofilicidade. ${ }^{10}$ Essa elevada afinidade por água traz consequências

*e-mail: odilio@cnpdia.embrapa.br indesejáveis como a redução da estabilidade estrutural do polímero. Ou seja, a presença constante de umidade na estrutura do polissacarídeo provoca o intumescimento da matriz com consequente desagregação das fibras além do favorecimento ao ataque por micro-organismos. Uma série de trabalhos tem sido proposta para reduzir o grau de hidrofilicidade com o uso de agentes entrecruzantes hidrofóbicos, como o glutaraldeído, que adicionado à cadeia da quitosana eleva sua estabilidade e reduz sua afinidade por moléculas polares. ${ }^{11}$

O emprego de técnicas de plasma a frio para o implante de radicais ou para a polimerização de monômeros organossilanos também tem sido avaliado como uma metodologia possível para alterações das características hidrofóbicas em polímeros. ${ }^{12-14} \mathrm{~A}$ ação do plasma sobre uma superfície orgânica pode promover reações de polimerização distintas das convencionais em função das energias envolvidas no ambiente de plasma e da descarga que ocorre in situ, o que usualmente leva à formação de entrecruzamentos altamente ramificados e insolúveis, estabelecendo uma matriz muito mais homogênea que as conseguidas por via úmida..$^{14,15}$

Diversos autores têm apresentado e discutido resultados do efeito do plasma sobre substratos poliméricos, contudo, a quase totalidade desses tratamentos é focada na funcionalização e no aumento da molhabilidade de superfícies hidrofóbicas, ${ }^{12-16}$ elevando as qualidades de adesão ou de interações entre a superfície tratada e outros materiais. O objetivo do presente estudo é o inverso, isto é, o desenvolvimento de uma superfície hidrofóbica sobre um filme tipicamente hidrofílico.

Silanos e organossilanos são os precursores mais empregados em plasma na formação de superfícies hidrofóbicas, particularmente o hexametildissilazano $\left(\mathrm{C}_{6} \mathrm{H}_{19} \mathrm{Si}_{2} \mathrm{~N}\right)$, comumente referido como HMDS, é um reagente de baixo custo e altamente empregado para este fim. ${ }^{12,17,18} \mathrm{Em}$ função de sua baixa toxicidade, depósitos de HMDS têm sido considerados adequados para modificações de características superficiais em madeiras, lignoceluloses e sementes, ${ }^{19-21}$ criando superfícies com características repelentes. Neste trabalho o efeito do depósito de HMDS sobre filmes de quitosana é avaliado com respeito às alterações na molhabilidade, absorção e permeação ao vapor de água.

\section{PARTE EXPERIMENTAL}

Os filmes foram preparados por casting sobre superfície apolar plana de acrílico. A solução precursora foi quitosana comercial de 
média massa molar (Sigma), na concentração de 1,0 g/L, dissolvida em solução aquosa de ácido acético a $1 \%$. Após a evaporação espontânea do solvente os filmes foram manualmente destacados. A espessura foi medida fazendo-se uso de um micrômetro (Scherr-Tumico), tomando-se cinco medidas em posições aleatórias de cada amostra.

A deposição de HMDS se deu por plasma a frio em um reator convencional de placas paralelas (PlasmaLab 80Plus da Oxford). Os filmes foram posicionados entre os eletrodos (aproximadamente 11 cm de cada eletrodo), fixados por garras metálicas e a câmara inicialmente evacuada a $<10$ mTorr. O HMDS (Sigma) foi controladamente admitido, mantendo-se estabilizado à pressão constante. O plasma foi aplicado a uma potencia de $60 \mathrm{~W}$ na frequência de $13,56 \mathrm{MHz}$ a uma pressão interna de 180 mTorr. Três tratamentos foram avaliados para descargas de plasma durante 2, 5 e $10 \mathrm{~min}$.

Os ângulos de contato foram medidos na temperatura ambiente usando-se gotas de água deionizada no volume de $10 \mu \mathrm{L}$. Empregou-se sistema de medida Tantec CAM-PLUS meter. Para cada filme, cinco medidas foram realizadas e tomou-se como referência superfície sem tratamento.

O grau de intumescimento foi medido pela técnica de imersão, segundo procedimento descrito por Liu et al., ${ }^{22}$ ou seja, amostras dos filmes foram cortadas e imersas em água deionizada por $4 \mathrm{~h}$ na temperatura ambiente. Após esse período, os filmes foram cuidadosamente retirados, o excesso superficial de água removido com filtro de papel e as amostras pesadas. $\mathrm{O}$ grau de intumescimento foi expresso como a porcentagem de ganho de massa, comparada com a massa inicial, de acordo com:

$$
D S=\frac{W_{s}-W_{d}}{W_{d}}(100 \%)
$$

sendo DS o grau de intumescimento, Ws a massa do filme após imersão e Wd a massa da amostra seca anterior à imersão. Todas as medidas foram realizadas em triplicata.

A permeação por vapor de água (WVP) foi determinada usandose uma adaptação do método do copo. ${ }^{23}$ Para tanto, $10 \mathrm{~mL}$ de água destilada foram colocados em um recipiente cilíndrico nas dimensões de $50 \mathrm{~cm}$ de diâmetro por $1,0 \mathrm{~cm}$ de profundidade. $O$ filme foi posicionado na abertura superior e fixado com vedação elástica a uma distância da água de aproximadamente $0,3 \mathrm{~cm}$. A área efetiva de permeação foi de $19,63 \mathrm{~cm}^{2}$. As medidas foram realizadas na temperatura ambiente em câmara de umidade relativa controlada a $40 \%$. Cada copo foi pesado a cada $2 \mathrm{~h}$, ao longo de 24 h, empregando-se uma balança analítica para o registro da variação de perda de massa. A taxa de permeação de vapor de água foi calculada normalizando-se a área exposta segundo a Equação 2:

$W V T=\left(\frac{\text { mass } a \mathrm{H}_{2} \mathrm{O} \text { perdida }}{\text { tempo } \times \text { área }}\right) \cdot$ espessura $\left(\frac{\mathrm{g}}{\mathrm{mh}}\right)$

\section{RESULTADOS E DISCUSSÃO}

As amostras com tratamento não apresentam qualquer alteração textural perceptível, sendo visualmente idênticas às referências (amostras não tratadas). A deposição de plasma de HMDS é uma técnica bem conhecida e amplamente empregada na indústria microeletrônica. O monômero do HMDS se polimeriza em estruturas do tipo silicone, com fortes ligações $\mathrm{Si}-\mathrm{N}-\mathrm{Si}$, além de ligações do tipo $\mathrm{Si}-\mathrm{O}-\mathrm{Si}$, Si-H, Si-C, C-H e C=O. ${ }^{24}$ Em princípio, espera-se que sobre a superfície da quitosana o HMDS reaja preferencialmente com os grupos hidroxilas resultando na formação de depósitos com presença de terminais $\mathrm{CH}_{3}$ e/ou $\mathrm{CH}_{2},{ }^{25}$ que conferem alta resistência à permeação de água. Contudo, as altas energias impingidas pelas partículas na condição de plasma podem induzir, pelo bombardeamento sobre o substrato polimérico, a geração de produtos voláteis. Essas moléculas, muitas delas polares, além de alterarem a composição do ambiente de plasma, podem ser incorporadas na camada em crescimento. Essa condição leva à formação de depósitos irregulares, com falhas estruturais ou sem uma composição química bem definida, ${ }^{12}$ o que pode interferir na ação protetora do filme reduzindo a eficiência de seu caráter hidrofóbico. Nesse sentido, é esperado que um maior tempo de ação do plasma e, consequentemente, um maior volume de moléculas polimerizadas, possa ter efeito na formação de uma película mais espessa e/ou mais homogênea, otimizando as propriedades desejadas.

Neste contexto, o efeito do tempo de tratamento sobre o ângulo de contato está disposto na Tabela 1, para medidas realizadas imediatamente após a deposição das gotas. Na literatura encontramos uma série de intervalos de molhabilidade para quitosanas não entrecruzadas, com ângulos variando entre $60^{\circ}{ }^{26} \mathrm{a} 83^{\circ} .^{22} \mathrm{Em}$ nosso material referência este ângulo é de $64^{\circ}$ e com o tratamento de HMDS, temos que, para descargas com 2 min, há um aumento médio em $24^{\circ}$ no ângulo medido com relação à superfície de quitosana sem tratamento e um aumento em $32^{\circ}$ e $33^{\circ}$ para tempos de depósitos de 5 e $10 \mathrm{~min}$, respectivamente. Esses valores refletem o sucesso na formação de um depósito que altera a hidrofilicidade local, embora indiquem que tratamentos superiores a 5 min não mais elevam a hidrofocidade superficial, ou seja, 5 min indica ser suficiente para a formação de uma superfície homogênea nas condições aqui experimentadas.

Tabela 1. Ângulo de contato em função do tempo de descarga de plasma de HMDS

\begin{tabular}{cc}
\hline Tempo de tratamento $(\mathrm{min})$ & Ângulo de Contato $\left({ }^{\circ}\right)$ \\
\hline 0 & $64 \pm 2^{\mathrm{a}^{\mathrm{a}}}$ \\
2 & $88 \pm 3^{\mathrm{b}}$ \\
5 & $96 \pm 2^{\mathrm{c}}$ \\
10 & $97 \pm 4^{\mathrm{c}}$ \\
\hline
\end{tabular}

*Letras diferentes indicam significância estatística em teste de Tukey $(\mathrm{p}<0.05)$

Esses valores de molhabilidade para as superfícies tratadas estão próximos ao apresentado por Hayakawa et al..$^{27}$ para depósitos de organossilanos por plasma sobre metais $\left(83^{\circ}\right)$, embora inferiores aos conseguidos por Tan et al. ${ }^{28}$ para tratamento de HMDS sobre papel $\left(120^{\circ}\right)$. De forma geral, pode-se afirmar que a molhabilidade é regida pela presença de grupos polares e não-polares em uma superfície, podendo-se arbitrariamente estabelecer que se o líquido molha em ângulos $0^{\circ}<\theta<90^{\circ}$ a superfície é considerada hidrofílica e hidrofóbica caso o ângulo medido esteja entre $90^{\circ}<\theta<180^{\circ},{ }^{29}$ embora fatores como rugosidade e pressão atmosférica tenham papeis importantes no ângulo medido.

Com respeito à absorção de água (intumescimento), o tempo de tratamento mostrou ter uma influência ligeiramente maior. Na Figura 1 estão dispostos os valores após $4 \mathrm{~h}$ de ensaio, indicando uma diferença significativa na absorção de água nas amostras não tratadas com respeito às tratadas. Embora estatisticamente os valores individuais dos filmes submetidos ao plasma sejam próximos, a taxa de absorção apresenta uma redução gradativa em função do tempo de deposição. Temos para 2 min uma redução média próxima a 33\% se comparada aos filmes não-tratados, chegando a $47 \%$ para os submetidos a 10 min de deposição.

O valor de intumescimento para a referência está em boa concordância com os valores padrão para absorção de água por quitosana em pH 7. ${ }^{30,31}$ A redução na absorção dos filmes tratados sugere que o processo de plasma é eficaz na formação de uma vedação hidro- 


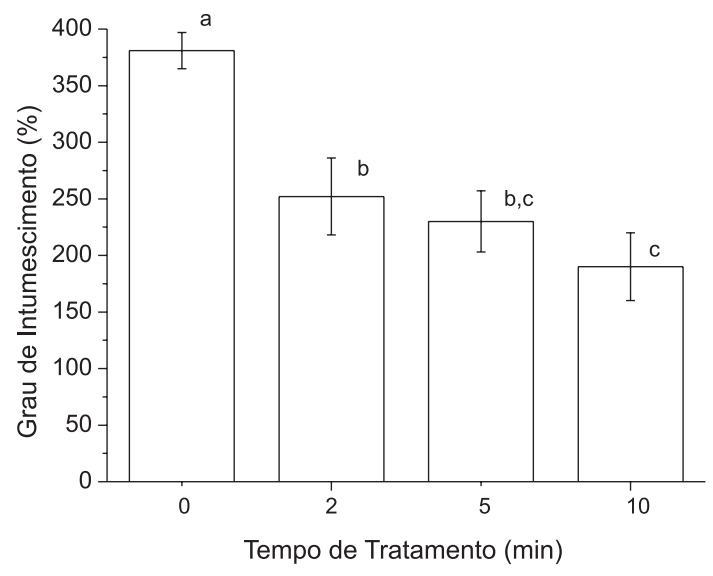

Figura 1. Grau de intumescimento após 24 h em imersão em água deionizada. Letras diferentes indicam significância estatística em teste de Tukey $(p<0,05)$

fóbica sobre a superfície polissacarídea, sendo esta otimizada em função do tempo de tratamento. Os mecanismos de intumescimento em polímeros são dependentes da contribuição relativa da difusão do penetrante e da estabilidade polimérica, que podem ser descritos em três etapas principais: ${ }^{32}$ tem-se, inicialmente, a adsorção física do penetrante sobre a superfície; com a saturação as moléculas tendem a migrar para a matriz associando-se aos grupos polares intermoleculares. Essa associação leva à solvatação dos grupos iônicos enfraquecendo as ligações de hidrogênio, o que gera uma expansão intercadeias; o afastamento das cadeias leva à geração de espaços na matriz que favorecem a subsequente penetração de água e demais moléculas movidas por forças polares associadas a mecanismos de capilaridade.

A incorporação de uma camada hidrofóbica impede o contato água-polissacarídeo, limitando os demais mecanismos. Como o depósito gerado não é livre de defeitos que possam levar à migração de umidade, o tempo de tratamento indica ser importante na formação de membranas mais protetoras. Este resultado vai de encontro ao estudo realizado com deposição de HMDS sobre superfície metálica que caracterizou que a estrutura do filme polimerizado varia em função do tempo de descarga, transitando de uma estrutura simples de sítios nucleados próxima a superfície do substrato para uma estrutura altamente entrecruzada quanto maior o tempo de descarga e a espessura do depósito. ${ }^{33}$

$\mathrm{O}$ aspecto de barreira pode ser melhor depreendido com respeito aos valores de permeação de vapor de água (Figura 2). Tem-se nesta figura a confirmação de que o tempo de exposição ao plasma reduz a capacidade de permeação de vapor de água através do sistema HMDS/ quitosana, embora, nas condições avaliadas, a película formada não barre totalmente a permeação.

Sabe-se que a permeação através de filmes é um processo multifatorial, controlado por defeitos e impurezas, sendo ainda mais complexo em sistemas multicamadas. ${ }^{34}$ Microvazios (pinholes) ou trincas longitudinais (cracks) são determinantes no transporte de gases. Estes defeitos não são formados somente durante a deposição das camadas, mas podem surgir como decorrência de estresses resultantes da interface entre dois materiais diferentes. ${ }^{35}$ A permeabilidade em filmes multicamadas pode ser expressa, em uma primeira aproximação, como a superposição das características individuais de cada camada levando em consideração efeitos de interface. Segundo Mildner et al. ${ }^{35}$ parâmetros de operação do plasma são igualmente fundamentais na formação de depósitos livres de defeitos, sendo principalmente uma combinação entre a pressão interna da câmara e a distância entre a descarga e o alvo decisivas para o crescimento de estruturas homogêneas.

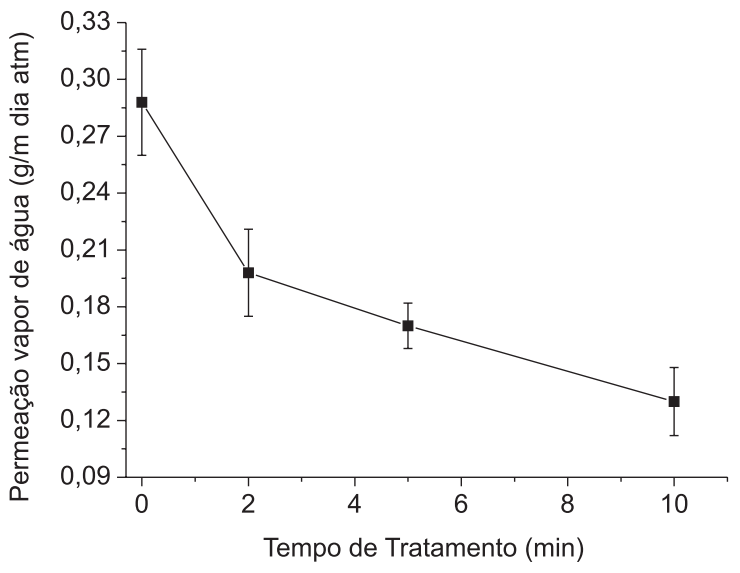

Figura 2. Permeação de vapor de água em função do tempo de tratamento em plasma de HMSD

\section{CONCLUSÕES}

A polimerização por plasma a frio de uma camada hidrofóbica sobre superfície orgânica hidrofílica, embora seja uma metodologia simples, ocorre como resultado de um processo complexo que envolve diversos parâmetros, nem todos controláveis. Em particular, a formação de uma superfície de HMDS sobre filmes finos de quitosana pode ser confirmada por medidas de molhabilidade, que acusam aumento nos ângulos de contato para valores tipicamente hidrofóbicos. A influência do tempo de exposição ao plasma na formação da camada fica mais bem definida nas medidas de intumescimento e de permeação de vapor de água. Para esses parâmetros observam-se reduções significativas dos valores em função do tempo de tratamento. Em princípio, o emprego da técnica de plasma a frio para a alteração da hidrofilicidade de superfícies de polissacarídeos aparenta ser uma metodologia viável, o que pode contribuir para uma maior aplicabilidade desses materiais.

\section{AGRADECIMENTOS}

À FAPESP por recursos recebidos e ao CNF (Cornell NanoScale Science \& Technology Facility) da Universidade de Cornell (USA), pelo uso do laboratório de plasma.

\section{REFERÊNCIAS}

1. Kubota, N.; Tastumoto, N.; Sano, T.; Toya, K.; Carbohydr. Res. 2000, 324, 268.

2. Roberts, G. A.; Chitin Chemistry, $1^{\text {st }}$ ed., MacMillan Press Ltd: Hong Kong, 1992, cap. 1.

3. Rabea, E. I.; Badawy, M. E.-T.; Stevens, C. V.; Smagghe, G.; Steurbaut, W.; Biomacromolecules 2003, 4, 1457.

4. Britto, D.; Campana Filho, S. P.; Assis, O. B. G.; Polímeros 2005, 15, 129.

5. Park, H. J.; Trends Food Sci. Tech. 1999, 10, 254.

6. Nettles, D. L.; Elder, S. H.; Gilbert, J. A.; Tissue Eng. 2002, 8, 1009

7. Assis, O. B. G.; Britto, D.; J. Polym Environ. 2008, 16, 192.

8. Olabarrieta, I.; PhD Thesis, Kungliga Tekniska Högskolan, Stockholm, Sweden, 2005.

9. Assis, O. B. G.; Hotchkiss, J. H.; Pack Tech. Sci. 2007, 20, 293.

10. Assis, O. B. G.; Silva, V. L.; Polímeros 2003, 13, 223.

11. Beppu, M. M.; Arruda, E. J.; Santana, C. C.; Polímeros 1999, 9, 163.

12. Arefi, F.; Andre, V.; Motjtazer-Rahmati, P.; Amouroux, J.; Pure Appl. Chem. 1992, 64, 715 .

13. Hegemann, D.; Brunner, H.; Oehr, C.; Plasmas and Polymers 2001, 6, 221 . 
14. Morosoff, N. Em Plasma Deposition Treatment and Etching of Polymers; d'Agostino, R., ed.; Academic Press Inc.: Boston, 1990, cap. 1.

15. Rau, C.; Thin Solid Films 1994, 249, 28.

16. Coops, I. H.; Gifkins, K. J.; J. Macromol. Sci., Part A: Pure Appl. Chem. 1982, 17, 217.

17. Santana, R. G.; Honda, R. Y.; Algatti, M. A.; Kayama, M. E.; Mota, R. P.; Polymer Preprints 1997, 38, 1029

18. Eib, N. K.; Mittal, K. L.; Friedrichs, A.; J. Appl. Polym. Sci. 1980, 25 , 2435.

19. Assis, O. B. G.; Ciência Rural 2005, 35, 219.

20. Denes, A. R.; Tshabalala, M. A.; Rowell, R.; Denes, F.; Young, R. A.; Holzforschung 1999, 53, 318.

21. Carvalho, R. A. M.; Carvalho, A. T.; Silva, M. L. P.; Demarquette, N. R.; Assis, O. B. G.; Quim. Nova 2005, 28, 1006.

22. Liu, Y-L.; Su, Y-H.; Lee, K-R.; Lai, J-Y.; J. Membr. Sci. 2005, 251, 233.

23. Han, C.; Zhao, Y.; Leonard, S. W.; Traber, M. G.; Postharvest Biol. Technol. 2004, 33, 67.

24. van Ooij, W. J.; Eufinger, S.; Guo, S.; Plasma Chem. Plasma Proc. 1997, $17,123$.

25. Fonseca, J. L. C.; Tasker, S.; Apperley, D. C.; Badyal, J. P. S.; Macromolecules 1996, 29, 1705.
26. Mingyu, C.; Kai, G.; Jiamou, L.; Yandao, G.; Nanming, Z.; Xiufang, Z.; J. Biomaterials Appl. 2004, 19, 59.

27. Hayakawa, T.; Yoshinari, M.; Nemoto, K.; Biomaterials 2004, 25, 119.

28. Tan, I. H.; Silva, M. L. P.; Demarquette, N. R.; J. Mater. Chem. 2001, 11,1019 .

29. Bose, A. Em Wettability; Berg, J. C., ed.; Marcel Dekker: New York, 1993, cap. 3.

30. Öztop, H. N.; Saraydin, D.; Çetinus, S.; Appl. Biochem. Biotechnol. 2002, 10, 239.

31. Mangala, E.; Kumar, T. S.; Baskar, S.; Rao, K. P.; Trends Biomater. Artif. Organs 2003, 17, 34 .

32. De Angelis, C. D.; Segre, A.; Crescenzi, V.; Polymer Preparation 2001, $42,45$.

33. Eufinger, S.; van Ooij, W. J.; Conners, K. D.; Surf. Interf. Analysis 1996, 24,841 .

34. Hanika, M.; Langowski, H-C.; Moosheimer, U.; Peukert. W.; Chem. Eng. Technol. 2003, 26, 605.

35. Mildner, M.; Korzec, D.; Engemann, J.; J. Surf. Coat. Technol. 1999, 112,366 